\title{
Manajemen Pemupukan Tanaman Kelapa Sawit (Elaeis guineensis Jacq.) pada Area Marjinal di Kabupaten Kotawaringin Timur, Kalimantan Tengah
}

\author{
Fertilization Management of Palm Oil (Elaeis guineensis Jacq.) on Marginal Area in East Kotawaringin, \\ Central Kalimantan
}

\author{
Weni Riska Octaviany, Hariyadi*
}

Departemen Agronomi dan Hortikultura, Fakultas Pertanian, Institut Pertanian Bogor (Bogor Agricultural University), Jl. Meranti, Kampus IPB Darmaga, Bogor 16680, Indonesia Telp. \& Faks.62-251-8629353 e-mail agronipb@indo.net.id

*Penulis untuk korespondensi: hariyadi@rocketmail.com

Disetujui 14 November 2016/Published online 8 Desember 2016

\begin{abstract}
Research has been implemented from February to May, 2012 in East Kotawaringin, Central Kalimantan. Internship activities aimed to find out, train and understand the management palm oil plantations especially fertilization management. The collection of data and information was carried out by the direct method and the indirect method. The direct method was carried out to obtain primary data in the field through observations ranging from preparation to implementation of cultivating, fertilizing effectiveness and efficiency through the principle of 5T, direct discussion with Estate manager (EM) and the assistant as well as employee. The indirect method is performed to obtain the secondary data from the garden office such as general conditions of the corporation, the climate condition and a type of soil, the condition of a plant, the organizational structure, production data and data related to activity of fertilization. Primary and secondary data is analyzed with descriptive and quantitative methods. Implementation of fertilizing in this Estate is generally pretty good ranging from preparation to implementation of fertilizing. Fertilizing effectiveness and efficiency with the principles of 5T are not good enough. Therefore, supervision and infrastructure improvements should be done correctly to improve the quality of fertilizing.
\end{abstract}

Keywords : fertilization management, marginal area, palm oil, principle of $5 T$

\section{ABSTRAK}

Kegiatan penelitian telah dilaksanakan pada bulan Februari hingga Mei 2012 di Kotawaringin Timur, Kalimantan Tengah. Kegiatan penelitian ini bertujuan untuk meningkatkan pengetahuan tentang budidaya kelapa sawit, memperoleh pengetahuan teknis dan manajerial perkebunan kelapa sawit, serta secara khusus mempelajari manajemen pemupukan tanaman kelapa sawit. Pengumpulan data dan informasi dilakukan dengan metode langsung dan metode tidak langsung. Metode langsung dilakukan untuk memperoleh data primer di lapangan melalui pengamatan mulai dari persiapan pemupukan sampai pelaksanaan pemupukan dengan prinsip 5T, diskusi langsung dengan manajer dan asisten kebun sebagai pekerja. Metode tidak langsung dilakukan untuk memperoleh data sekunder seperti kondisi umum perusahaan, kondisi iklim dan jenis tanah, kondisi tanaman, struktur organisasi, data produksi dan data yang terkait dengan kegiatan pemupukan. Data primer dan sekunder dianalisis dengan metode deskriptif dan kuantitatif. Pelaksanaan pemupukan di kebun ini secara umum belum cukup baik mulai dari pengadaan pupuk sampai pelaksanaan pemupukan. Efektifitas dan efisiensi pemupukan belum sepenuhnya sesuai prinsip 5T. Oleh karena itu pengawasan yang lebih baik dari mandor pupuk dan asisten kebun harus ditingkatkan guna memperbaiki kualitas pemupukan berikutnya.

Kata kunci : area marjinal, manajemen pemupukan, minyak kelapa sawit, prinsip $5 T$ 


\section{PENDAHULUAN}

Kelapa Sawit (Elaeis guineensis Jacq) merupakan tanaman penghasil minyak nabati yang mempunyai keunggulan lebih tinggi dibandingkan tanaman penghasil minyak nabati lainnya seperti kedelai dan biji bunga matahari. Prospek komoditi minyak kelapa sawit dalam perdagangan minyak nabati dunia telah mendorong pemerintah maupun swasta untuk memacu pengembangan areal perkebunan kelapa sawit. Hal ini berkaitan dengan keterbatasan lahan potensial yang tersedia di Indonesia. Pengembangan areal kelapa sawit sudah mengarah ke lahan-lahan marjinal yang umumnya berada di daerah luar pulau jawa seperti lahan marginal kering (pasir) dan lahan marginal basah (lahan gambut, pasang surut, sulfat masam) yang berada di Kalimantan Tengah.

Lahan marjinal adalah lahan yang memiliki mutu rendah karena memiliki beberapa faktor pembatas jika digunakan untuk suatu keperluan tertentu.Salah satu lahan marginal yang terdapat di Kalimantan Tengah adalah lahan marginal berpasir. Pada tanah dengan tekstur pasir, daya serap tanah terhadap pupuk rendah, akibatnya pupuk mudah hilang hilang dari tanah dan menyebabkan penurunan produksi (Suwardi dan Sastiono, 2009).

Pemupukan menjadi faktor penting dalam upaya mencapai produktivitas yang tinggi (Darmosarkoro et al., 2003). Pemupukan yang baik mampu meningkatkan produksi hingga mencapai produktivitas standar sesuai dengan kelas keseuaian lahannya (Sutarta et al,. 2003). Biaya pemupukan yang tinggi menuntut pihak praktisi perkebunan untuk secara tepat melakukan manajemen pemupukan dengan menerapkan kaidah efektifitas dan efiseiensi pemupukan mulai dari penentuan jenis pupuk dan dosis sampai dengan aplikasi di lapangan agar dapat mencapai produktivitas sesuai dengan kelas kesesuaian lahannya (S3).

Kegiatan penelitian ini bertujuan meningkatkan pengetahuan tentang budidaya kelapa sawit, serta memperoleh pengetahuan pengelolaan teknis dan manajerial di lapangan pada berbagai level pekerjaan. Secara khusus mempelajari manajemen pemupukan pada tanaman kelapa sawit pada lahan marjinal, serta menganalisis faktor-faktor yang mempengaruhi kegiatan pemupukan dan memberikan rekomendasi solusi dari permasalahan yang terjadi.

\section{BAHAN DAN METODE}

Kegiatan penelitian dilaksanakan bulan Februari - Mei 2012, di Kecamatan Cempaga
Hulu, Kabupaten Kotawaringin Timur, Kalimantan Tengah. Luas area sebesar 3765 ha yang dibagi menjadi lima divisi. Divisi 1 memiliki luas area sebesar 850 ha, Divisi II 756 ha, Divisi III 705 ha, Divisi IV 725 ha, dan Divisi V 730 ha.

Pengumpulan data dilakukan dengan mengumpulkan data primer dan data sekunder. Data primer diperoleh dengan pengamatan secara langsung di lapangan terhadap semua kegiatan teknis yang dilaksanakan, sedangkan data sekunder diperoleh dari kantor kebun meliputi lokasi dan letak geografis kebun, keadaan tanaman, iklim dan jenis tanah, luas areal dan tata guna lahan, produksi kebun, norma kerja di lapangan, data rekomendasi dan realisasi pemupukan. Pengamatan dilakukan terhadap prinsip 5T (Tepat Jenis, Tepat Waktu, Tepat Dosis, Tepat Cara, dan Tepat Administrasi), kehilangan pupuk akibat pengangkutan, upaya efisiensi pupuk, dan produktivitas kebun.

Data dan informasi yang diperoleh dari kegiatan penelitian dianalisis secara kuantitatif seperti nilai rata-rata, persentase dan perhitungan statistik sederhana lalu dijelaskan secara deskriptif.

\section{HASIL DAN PEMBAHASAN}

\section{Keadaan Iklim dan Tanah}

Berdasarkan data stasiun klimatologi Departemen Riset BGA Metro Pundu pada tahun 2011, suhu udara rata-rata di SDME adalah $26.7{ }^{\circ} \mathrm{C}$ dengan suhu maksimal mencapai $31.4{ }^{\circ} \mathrm{C}$ dan suhu minimal mencapai $23.7{ }^{\circ} \mathrm{C}$. Rata-rata curah hujan pada tahun 2008-2011 adalah $3298.15 \mathrm{~mm} /$ tahun dengan rata-rata hari hujan adalah 108 hari/tahun. Berdasarkan klasifikasi menurut Schmidt Ferguson, tipe iklim adalah tipe iklim A.

Jenis tanah berdasarkan data jenis tanah 2011 terdiri dari tanah inceptisol sebesar 64.7\%, entisol sebesar $30.4 \%$ dan ultisol sebesar $4.7 \%$. Hasil tersebut menunjukkan bahwa mayoritas jenis tanah merupakan inceptisol. Kesesuaian lahan aktual untuk tanaman kelapa sawit termasuk dalam kelas S3 dengan faktor pembatas tekstur tanah berpasir.

\section{Kondisi Tanaman dan Produktivitas}

Varietas kelapa sawit yang digunakan adalah varietas Tenera Marihat yang dihasilkan oleh Pusat Penelitian Kelapa Sawit (PPKS), PNG, Socfindo, dan Costa Rica. Jarak tanam yang digunakan adalah $9.2 \mathrm{~m} \times 9.2 \mathrm{~m} \times 9.2 \mathrm{~m}$ dengan populasi 136 pokok per hektar. Tanaman kelapa sawit terdiri dari tanaman kelapa sawit belum menghasilkan (TBM) dan tanaman menghasilkan (TM). Terdapat enam tahun tanam yaitu 2004, 
2005, 2006, 2007, 2008, dan 2009. Produktivitas (ton/ha/tahun) TBS di divisi 2 pada tahun 2008, 2009, 2010, dan 2011 adalah 3.5, 4.1, 8.7, dan 12 ton/ha/tahun.

\section{Pemupukan}

Pupuk yang digunakan di kebun adalah pupuk organik dan pupuk anorganik. Pemupukan organik dilakukan dengan mengapliksikan janjang kosong pada pokok kelapa sawit, sedangkan pemupukan anorganik dilakukan dengan mengapliksikan pupuk Urea $\left(\mathrm{CO}\left(\mathrm{NH}_{2}\right)_{2}\right)$, RP $\left(\mathrm{Ca}\left(\mathrm{PO}_{4}\right)_{2}\right)$, MOP $(\mathrm{KCl}), \quad \mathrm{HGFB}\left(\mathrm{B}_{2} \mathrm{O}_{3}\right), \mathrm{Zn}$ $\left(\mathrm{ZnSO}_{4} \cdot \mathrm{H}_{2} \mathrm{O}\right), \mathrm{Cu}\left(\mathrm{CuSO}_{4} \mathrm{H}_{2} \mathrm{O}\right)$, Palmo (14-8-212), dan Kieserit $\left(\mathrm{MgSO}_{4} \cdot \mathrm{H}_{2} \mathrm{O}\right)$.

Janjang kosong merupakan limbah yang dihasilkan dari pabrik kelapa sawit. Menurut Darmosarkoro et al. (2003) janjang kosong kelapa sawit mengandung $42.8 \% \mathrm{C}, 2.90 \% \mathrm{~K}_{2} \mathrm{O}, 0.80 \%$ $\mathrm{N}, \quad 0.22 \% \quad \mathrm{P}_{2} \mathrm{O}_{5}, 0.30 \% \mathrm{MgO}$ dan unsur-unsur mikro antara lain $10 \mathrm{ppm} \mathrm{B}, 23 \mathrm{ppm} \mathrm{Cu}$, dan 51 ppm Zn.

Aplikasi janjang kosong sangat efektif sebagai mulsa, karena dapat menurunkan temperatur tanah, mempertahankan kelembaban tanah dan mengurangi dampak yang kurang baik terhadap pertumbuhan dan produksi pada musim kemarau. Untuk area dengan curah hujan tinggi, janjang kosong dapat mengurangi kehilangan nutrisi melalui proses pencucian dan aliran permukaan. Pada tanaman belum menghasilkan (TBM) disebar mengelilingi pokok $30 \mathrm{~cm}$ dari pangkal pokok. Pada tanaman menghasilkan (TM) diaplikasikan di gawangan atau di antara dua pokok dalam barisan tanaman dengan dosis 200 kg/pokok. Aplikasi janjang kosong dilakukan secara merata satu lapis untuk menghindari berkembangnya hama Oryctes rhinoceros.

Rekomendasi pemupukan diberikan oleh Departemen Riset BGA berdasarkan hasil analisis daun. Pupuk yang digunakan perusahaan yaitu Urea,MOP, HGFB, RP, Kieserit, Palmo, dan Zincooper. Pemesanan pupuk yang dibutuhkan kebun dilakukan oleh

\section{Prinsip 5 Tepat}

Pemupukan yang efektif dan efisien dapat dicapai dengan memperhatikan beberapa hal yaitu, jenis dan dosis pupuk, cara pemberian pupuk, waktu, dan admisnitrasi pemupukan.

Tepat jenis. Pemilihan jenis pupuk yang diberikan pada pokok kelapa sawit mempertimbangkan kebutuhan tanaman dan ketersediaan hara. Jenis pupuk yang digunakan berdasarkan rekomendasi yang diberikan Departemen Riset BGA (Tabel 1). Pahan (2010) menyatakan bahwa strategi dalam menentukan jenis pupuk ditentukan oleh pertimbangan teknis dan pertimbangan ekonomis. Pertimbangan teknis meliputi sifat pupuk dan sifat tanah, sebab puuk yang diaplikasikan akan sangat menentukan efisiensi pemupukan.

Tabel 1. Jenis pupuk yang digunakan di divisi 2

\begin{tabular}{clllll}
\hline Unsur kimia & Jenis pupuk & Rumus kimia & \multicolumn{1}{c}{ Kadar hara utama } & \multicolumn{1}{c}{ Bentuk } & Warna \\
\hline $\mathrm{N}$ & Urea & $\left(\mathrm{NH}_{2}\right)_{2} \mathrm{CO}$ & $42-46 \% \mathrm{~N}$ & Kristal dan butir & Putih \\
$\mathrm{P}$ & $\mathrm{RP}$ & $\mathrm{Ca}_{3}\left(\mathrm{H}_{3} \mathrm{PO}_{4}\right)_{2}$ & $25-38 \% \mathrm{P}_{2} \mathrm{O} 5$ & Tepung & Abu-abu \\
$\mathrm{K}$ & $\mathrm{MOP}$ & $\mathrm{KCl}$ & $60-62 \% \mathrm{~K}_{2} \mathrm{O}, 47 \% \mathrm{Cl}$ & Kristal & Merah,putih,kotor \\
$\mathrm{Mg}$ & Kiserit & $\mathrm{MgSO}_{4} \cdot \mathrm{H}_{2} \mathrm{O}$ & $27 \% \mathrm{MgO}, 23 \% \mathrm{~S}$ & Kristal, tepung & Puth abu-abu \\
$\mathrm{B}$ & $\mathrm{HGFB}$ & $\mathrm{Na}_{2} \mathrm{~B}_{4} \mathrm{O}_{7} .5 \mathrm{H}_{2} \mathrm{O}$ & $45 \% \mathrm{~B}_{2} \mathrm{O}_{5}$ & Kristal & Putih kotor \\
$\mathrm{Cu}$ & Cooper & $\mathrm{CuSO}_{4} 7\left(\mathrm{H}_{2} \mathrm{O}\right)$ & $25.5 \% \mathrm{Cu}, 12.5 \% \mathrm{~S}$ & Kristal & Biru \\
$\mathrm{Zn}$ & Zinc & $\mathrm{ZnSO}_{4} \mathrm{H}_{2} \mathrm{O}$ & $36 \% \mathrm{Zn}$ & Kristal & Biru \\
\hline
\end{tabular}

Tepat waktu. Waktu aplikasi pupuk didasarkan pada pola curah hujan di daerah tersebut. Umumnya semua pupuk tepat diaplikasikan pada bulan dengan curah hujan cukup yaitu $100-300 \mathrm{~mm} / \mathrm{bulan}$.

Berdasarkan Tabel 2 waktu pemupukan yang dilakukan sudah cukup tepat dari rekomendasi yang diberikan oleh Departemen Riset BGA. Akan tetapi pada pupuk Urea dan MOP tidak tepat diaplikasikan pada bulan April, karena curah hujan rata-rata di atas $300 \mathrm{~mm}$ yang berpotensi losses tinggi melalui prose pencucian, aliran permukaan dan erosi. Darmosarkoro et al. (2003) menyatakan untuk menghindari pencucian pupuk, waktu pemupukan ditentukan berdasarkan distribusi curah hujan bulanan. Pemupukan dilakukan pada bulan dengan curah hujan $>60$ $\mathrm{mm} /$ bulan, namun tidak pada puncak musim hujan. Aplikasi pemupukan di lapangan dapat terhambat atau berubah disebabkan karena pengadaan pupuk dan persiapan lapangan serta curah hujan yang tidak dapat diprediksi, karena curah hujan sangat berpengaruh penting dalam keefektifan pemupukan. Hal tersebut menentukan tingkat penyerapan hara pupuk dan kemungkinan kehilangan hara. 
Tabel 2. Rekomendasi dan realisasi pemupukan rotasi 1

\begin{tabular}{ccc}
\hline \multirow{2}{*}{ Bulan } & Jenis Pupuk & $\begin{array}{c}\text { Curah hujan } \\
\text { (mm/bulan) }\end{array}$ \\
\cline { 2 - 3 } & RP HGFBZincopPalmo MOP Urea & \\
\hline Jan & Rekomendasi & 316 \\
Feb & & 258 \\
Mar & 375 \\
Apr & & 441 \\
Mei & & 221 \\
\hline & & \\
\hline Jan & Realisasi & 316 \\
Feb & & 258 \\
Mar & & 375 \\
Apr & 441 \\
Mei & & 221 \\
\hline
\end{tabular}

Tepat dosis. Pengamatan ketepatan bobot untilan dilakukan pada pupuk HGFB, Urea, dan MOP dengan melakukan penimbangan contoh 10 untilan di gudang pupuk. Berdasarkan Tabel 3 terlihat bahwa persentase ketepatan bobot untilan dari ketiga jenis pupuk adalah 99.79\%. Hal tersebut menunjukkan bahwa hasil yang diperoleh masih dalam batas toleransi yang ditetapkan pihak kebun yaitu $\pm 5 \%$ atau $95-105 \%$. Penetapan toleransi tersebut dilakukan dengan mempertimbangkan hal-hal seperti ketelitian takaran pupuk ataupun timbangan dan kehilangan pupuk dari mulai pengangkutan sampai diaplikasikan ke pokok kelapa sawit. Oleh karena itu, penguntilan dapat dikatakan baik sehingga diharapkan dapat mencapai ketepatan dosis per pokok di lapangan.

Tabel 3. Rata-rata ketepatan bobot untilan pupuk HGFB, Urea, dan MOP

\begin{tabular}{|c|c|c|c|c|c|}
\hline \multirow{2}{*}{ Jenis pupuk } & \multicolumn{3}{|c|}{ Penguntilan ke- } & \multirow{2}{*}{ Rata-rata ketepatan bobot untilan } & \multirow{2}{*}{ Bobot yang ditetapkan $(\mathrm{kg})$} \\
\hline & 1 & 2 & 3 & & \\
\hline & & & & $\ldots . .(\%) \ldots \ldots \ldots$ & \\
\hline HGFB & 100.07 & 88.38 & 105.22 & 97.89 & 13.60 \\
\hline Urea & 100.75 & 104.81 & 100.56 & 102.04 & 10.60 \\
\hline MOP & 98.88 & 99.78 & 99.80 & 99.46 & 14.10 \\
\hline Rata-rata & 99.9 & 97.65 & 101.86 & 99.79 & \\
\hline
\end{tabular}

Ketepatan dosis untilan per pokok dilakukan pada pupuk Palmo, Urea, dan MOP di tiga blok berbeda untuk masing-masing jenis pupuk dengan pengambilan contoh masing-masing 10 untilan pada tujuh penabur. Perhitungan ketepatan dosis dilakukan berdasarkan bobot untilan setiap jenis pupuk dan dosis/pokok setiap blok. Contoh pada pupuk palmo di blok A25 dan A27, dosis yang diberikan adalah $2.25 \mathrm{~kg} /$ pokok, sehingga satu untilan dengan bobot $12.5 \mathrm{~kg}$ dapat diaplikasikan untuk enam tanaman. Dosis yang direkomendasikan pada blok A33 adalah 1.75 $\mathrm{kg} /$ pokok, sehingga 1 untilan dapat diaplikasikan untuk 7 pokok tanaman. Secara keseluruhan diperoleh ketepatan dosis untilan/pokok sebesar $84.70 \%$. Pemberian dosis pupuk per pokok di divisi 2 sudah cukup baik, akan tetapi belum mencapai standar yang ditetapkan kebun yaitu di atas 90\% (Tabel 4).

Permasalahan yang terjadi di lapangan diantaranya dosis yang diberikan pada tanaman di awal dan akhir baris lebih banyak dibandingkan dengan tanaman yang berada di tengah. Hal ini disebabkan masih terdapat pengecer yang meminta penabur untuk menghabiskan pupuk pada pokokpokok awal baris untuk megurangi beban pengecer. Selain itu pada blok tanaman belum menghasilkan (TBM) seperti pada blok A33, akses lahan yang masih dipenuhi kacangan menyulitkan penabur untuk menjangkau pokok kelapa sawit yang akan dipupuk.

Tabel 4. Ketepatan dosis untilan per pokok

\begin{tabular}{llccc}
\hline \multicolumn{1}{c}{ Jenis pupuk } & Blok & Rata-rata & Standar jumlah pokok per until & Ketepatan Dosis/pokok (\%) \\
\hline \multirow{3}{*}{ Palmo } & A25 & 6.30 & 6 & 95.23 \\
& A33 & 7.50 & 7 & 92.33 \\
& A27 & 6.70 & 6 & 89.55 \\
\hline Urea & B24 & 10.2 & 8 & 77.84 \\
& B25 & 10.2 & 8 & 77.84 \\
& B36 & 12.1 & 8 & 66.11 \\
MOP & C35 & 11.0 & 11 & 100.00 \\
\hline & C37 & 12.5 & 11 & 88.00 \\
\hline & C38 & 8.30 & 11 & 75.45 \\
\hline
\end{tabular}


Tepat cara. Cara pemupukan dapat menentukan hara yang diserap oleh tanaman. Agar dapat diserap oleh tanaman, unsur-unsur hara tersebut harus kontak dengan permukaan akar tanaman. Penempatan pupuk pada zona perakaran aktif akan meningkatkan efisiensi pemupukan. Pemupukan menggunakan dua cara, yaitu cara tabur dan cara tugal (lubang). Pupuk yang diaplikasikan dengan cara tabur diantaranya Urea, MOP, RP, HGFB, dan Kieserit, sedangkan pupuk Palmo dan C. Zincooper diaplikasikan dengan cara tugal (lubang).

Pengamatan dilakukan terhadap ketepatan cara tugal pada pupuk Palmo dan C. Zincooper dengan 280 contoh tanaman dari tujuh orang penabur pada dua blok yang berbeda. Ketentuan yang ditetapkan untuk cara aplikasi pupuk Palmo (14-8-21-2) dan C. Zincooper adalah dengan dibuat empat lubang pada masing-masing sisi pokok kelapa sawit.

Berdasarkan Tabel 5 diperoleh ketepatan cara tugal secara umum dari kedua pupuk tersebut sebesar $80.76 \%$. Hal tersebut belum menunjukkan ketepatan cara yang baik dalam pemupukan, karena masih di bawah 90\%. Permasalahan yang terjadi di lapangan diantaranya adalah masih ditemukan dalam satu KKP tidak terdapat kerja sama dan ketelitian yang baik. Sering terjadi antara pencangkul dan penabur berjarak terlalu jauh, sehingga lubang yang dibuat tidak terlihat oleh penabur yang mengakibatkan tidak dipupuk oleh penabur karena ketidaktelitiannya.

Tabel 5. Ketepatan cara tugal pada pupuk palmo dan zincooper

\begin{tabular}{cccc}
\hline Jenis Pupuk Blok & $\begin{array}{c}\text { Rata-rata Jumlah } \\
\text { (lubang) }\end{array}$ & $\begin{array}{c}\text { Ketepatan } \\
\text { Cara(\%) }\end{array}$ \\
\hline Palmo & A25 & 3.24 & 81.07 \\
& A27 & 3.17 & 79.29 \\
\hline Zincooper & A33 & 3.32 & 83.21 \\
& A30 & 3.17 & 79.46 \\
\hline Rata-Rata & & & 80.76 \\
\hline
\end{tabular}

Pupuk HGFB, Borat, Urea, dan MOP diaplikasikan dengan cara tabur. Penaburan pupuk untuk masing-masing pupuk berbeda satu sama lain sesuai dengan posisi perakaran yang aktif menyerap hara tersebut. Ketentuan yang ditetapkan adalah memupuk dengan $U$-shape.

Berdasarkan Tabel 6 rata-rata ketepatan cara untuk pupuk Urea dan MOP hanya $61.60 \%$. Sebagian besar penabur hanya melakukan penaburan pada sisi kanan dan kiri pokok kelapa sawit. Pokok-pokok dengan kondisi piringan yang bersih dan tanaman cukup tinggi pun masih banyak penabur yang tidak menabur secara $U$-shape. Penaburan secara $U$-shape hanya dilakukan pada pokok-pokok awal dan akhir.

Tabel 6. Ketepatan cara tabur pada pupuk Urea dan MOP

\begin{tabular}{|c|c|c|c|}
\hline \multirow{2}{*}{$\begin{array}{l}\text { Jenis } \\
\text { Pupuk }\end{array}$} & \multirow{2}{*}{ Blok } & Penabur & \multirow{2}{*}{$\begin{array}{c}\text { Ketepatan } \\
\text { Cara }\end{array}$} \\
\hline & & $\begin{array}{lllllll}1 & 2 & 3 & 4 & 5 & 6 & 7\end{array}$ & \\
\hline \multicolumn{4}{|c|}{ (\% U-Shape) } \\
\hline \multirow{3}{*}{ Urea } & B24 & 355585651009595 & 75.71 \\
\hline & $\mathrm{C} 32$ & 40753560506060 & 54.29 \\
\hline & C38 & $95358565 \quad 60 \quad 2540$ & 57.86 \\
\hline \multirow[t]{2}{*}{ MOP } & C37 & 65457055456070 & 58.57 \\
\hline & & Rata-rata & 61.60 \\
\hline
\end{tabular}

Permasalahan lain yang terjadi adalah kondisi lahan seperti kacangan yang tebal atau melilit ke pokok kelapa sawit, lahan rawa atau tergenang, dan gulma yang banyak menyebabkan ketepatan cara pemupukan (tugal dan tabur) tidak tercapai dengan baik. Ketepatan cara dari semua jenis pupuk yang diamati hanya diperoleh persentase sebesar $71.1 \%$. Hal ini menunjukkan bahwa tim BMS divisi 2 belum cukup baik dalam pelaksanaan cara pemupukan, karena standar yang ditetapkan kebun adalah di atas 90\%. Pengawasan asisten divisi dan mandor pupuk perlu ditingkatkan untuk dapat meningkatkan kualitas cara pemupukan di lapangan.

Tepat administrasi. Mandor until diwajibkan membawa Bon Permintaan dan Pengeluaran barang (BPPB) asli dari divisi sebagai tanda bahwa pupuk akan diambil. Asisten dan mandor pupuk berkumpul di kantor divisi setiap apel sore untuk menyelesaikan administrasi laporan realisasi kerja pemupukan sesuai dengan program yang dicatat di buku rekomendasi. Mandor pupuk juga membuat rencana kerja besok hari seperti jumlah untilan yang dibutuhkan pada blok yang akan diaplikasi, dan jumlah tenaga kerja.

\section{Kehilangan Pupuk}

Berdasarkan Tabel 7 dapat dikatakan bahwa kehilangan pupuk HGFB akibat pengangkutan cukup besar yaitu $1.677 \mathrm{~kg}$ dari ratarata bobot awal. Hal tersebut melebihi toleransi yang ditetapkan yaitu $\pm 5 \%$. Proses yang terjadi dari mulai penguntilan pupuk sampai kegiatan pengeceran menyebabkan kehilangan pupuk tersebut cukup besar. Pupuk yang dituangkan ke terpal tercecer ke lantai tanah, sehingga pupuk tersebut tertinggal dan tersapu pada kegiatan penguntilan. Kehilangan pupuk saat pelangsiran pupuk ke tempat peletakkan pupuk terjadi saat untilan dari kendaraan dilemparkan. Untilan tersebut juga terlempar ke parit sehingga pupuk tidak dapat digunakan dengan utuh. Kehilangan 
pupuk juga terjadi saat pengeceran pupuk karena pengecer yang kurang hati-hati dalam menumpahkan pupuk ke wadah.

Tabel 7. Rata-rata bobot kehilangan pupuk HGFB akibat pengangkutan

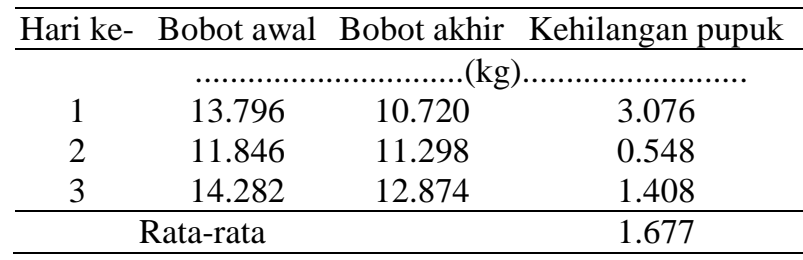

\section{Upaya Peningkatan Efisiensi Pemupukan}

Peningkatan efisiensi ketepatan pupuk dapat dilakukan dengan aplikasi bahan pembenah tanah, pengendalian gulma dan pembuatan silt pit. Hal yang berpengaruh terhadap efektivitas pemupukan adalah kapasitas tukar kation tanah. Semakin tinggi KTK tanah maka semakin tinggi kemampuan tanah untuk memegang hara yang diberikan. Cara yang dapat dilakukan untuk meningkatkan KTK tanah adalah dengan aplikasi bahan organik seperti janjang kosong dan pelepah hasil penunasan, selain itu dengan mempertahankan gulma lunak di sekitar piringan dapat menambah bahan organik tanah.

Pertumbuhan gulma yang tidak terkendali akan menjadi saingan bagi tanaman dalam menyerap unsur hara, sinar matahari dan air. Pengendalian gulma dapat dilakukan dengan tanaman penutup tanah seperti Mucuna bracteata. Tekstur tanah berpasir memiliki tekstur kasar sehingga menurunkan kemampuan tanah dalam menyerap air dan hara. Pengelolaan lahan dengan sistem konservasi sangat diperlukan untuk mempertahankan kesuburan tanah dan mencegah erosi. Pembuatan silt pit dapat meningkatkan efisiensi pemupukan dengan tujuan menangkap atau menahan run off yang membawa kandungan pupuk.

\section{Produktivitas}

$\begin{array}{ccr}\text { Pemupukan yang } & \begin{array}{r}\text { baik } \\ \text { meningkatkan produksi }\end{array} \text { hingga } & \text { mencapai }\end{array}$ produktivitas standar sesuai dengan kelas keseuaian lahannya (Sutarta et.al., 2003). Faktor yang mempengaruhi produktivitas kelapa sawit adalah pemupukan. Produktivitas masih di bawah standar produktivitas Marihat kelas lahan S3. Hal ini menunjukkan bahwa realisasi pemupukan belum berjalan dengan baik sesuai dengan rekomendasi pemupukan, sehingga efektivitas dan efisiensi pemupukan belum tercapai. Faktor lain yang dapat mempengaruhi belum tercapainya produktivitas pada standar Marihat adalah losses, pengawasan, dan kondisi lahan.

\section{KESIMPULAN}

Pelaksanaan pemupukan secara umum belum cukup baik dari mulai pengadaan pupuk sampai pelaksanaan pemupukan. Ketepatan jenis, waktu, dan administrasi pemupukan sudah sesuai dengan standar yang ditetapkan perusahaan, sedangkan ketepatan dosis dan cara belum mencapai standar yang ditetapkan. Ketepatan dosis pupuk dapat tercapai tepat pada blok, tetapi tidak pada setiap pokok kelapa sawit.

\section{DAFTAR PUSTAKA}

Darmosarkoro, W., Winarma, Sutarta, E.S. 2003. Teknologi pemupukan tanaman kelapa sawit. Prosiding Lahan dan Pemupukan Kelapa Sawit; Medan, Indonesia.

Sutarta, E.S., Rahutomo, S., Darmosarkoro, W., Winarma. 2003. Peranan unsur hara dan sumber hara pada pemupukan tanaman kelapa sawit. Prosiding Lahan dan Pemupukan Kelapa Sawit; Medan, Indonesia.

Suyatno, R. 2010. Masa Depan Perkebunan Kelapa Sawit. Yogyakarta (ID): Kanisius.

Suwardi, A., Sastiono. 2009. Peningkatan produksi kelapa sawit pada tanah-tanah bermasalah dengan aplikasi asam humat dan zeolit. Prosiding Seminar Hasil-Hasil Penelitian $I P B$; Bogor, Indonesia. 